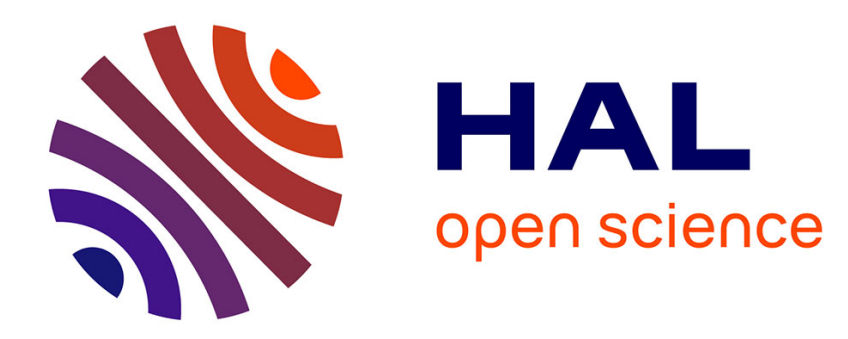

\title{
Prevention of zoonotic animal diseases: a step towards co-operation among Nordic authorities?
}

\author{
Heli Irmeli Koskinen
}

\section{To cite this version:}

Heli Irmeli Koskinen. Prevention of zoonotic animal diseases: a step towards co-operation among Nordic authorities?. Journal of Public Health, 2010, 18 (4), pp.385-390. 10.1007/s10389-009-0310-5 . hal-00535302

\section{HAL Id: hal-00535302 https://hal.science/hal-00535302}

Submitted on 11 Nov 2010

HAL is a multi-disciplinary open access archive for the deposit and dissemination of scientific research documents, whether they are published or not. The documents may come from teaching and research institutions in France or abroad, or from public or private research centers.
L'archive ouverte pluridisciplinaire HAL, est destinée au dépôt et à la diffusion de documents scientifiques de niveau recherche, publiés ou non, émanant des établissements d'enseignement et de recherche français ou étrangers, des laboratoires publics ou privés. 


\title{
Prevention of zoonotic animal diseases: a step towards co-operation among Nordic authorities?
}

\author{
Heli Irmeli Koskinen
}

Received: 7 April 2009 /Accepted: 30 November 2009/Published online: 6 January 2010

(C) Springer-Verlag 2009

\begin{abstract}
Aim With globalisation, the spreading and consequences of serious animal diseases will become an increasingly realistic threat, also to Nordic countries, their food animals and consumers. It has already been suggested that it might be useful to establish an army to manage all co-operations among countries, for instance, for medical co-operation needs. In light of this, it might also be important to guarantee the security of animal products and to fight together against animal diseases, some of which are potentially dangerous for human beings. The aim of this study was to investigate how the laws concerning animal diseases construct the reality of co-operation among authorities in different Nordic countries.

Subjects and Methods The laws were qualitatively analysed in the framework of discourse analysis.

Results The different situations in different Nordic countries were introduced. Uniform legislation among Finland, Sweden, Denmark and Norway was missing.

Conclusion In the future, the potential for real co-operation among not only authorities on the national level but also with those from different countries should be investigated.
\end{abstract}

Keywords Co-operation - Animal disease $\cdot$ Laws about animal diseases $\cdot$ Authority $\cdot$ Nordic country

\section{Introduction}

In animal agriculture, the needs of livestock owners have challenged veterinary services (Buntain 2004). These

H. I. Koskinen $(\bowtie)$

Department of Animal Science, University of Helsinki,

P.O. Box 28 (Koetilantie 5), FI-00014, Helsinki, Finland

e-mail: Heli.I.Koskinen@helsinki.fi services should include more accurate diagnosis of all the infectious and non-infectious components of diseases as well as quantification of the effects of disease or production losses, identification and quantification of costs for alternate intervention strategies and control strategies to prevent contact with infectious agents (bio-security), for instance (Larson 2004; Maccabe et al. 2008). Fortunately for animal agriculture, the skills needed by veterinarians treating animals used for food are also needed by several emerging segments of the veterinary profession, including environmental monitoring and management, bio-security and disease eradication, laboratory diagnostics and federal regulatory and bio-defence roles (Larson 2004).

Globalisation is one reason for the emergence of zoonotic infections (Chomel 2003; Maccabe et al. 2008). Recent events have demonstrated that in an increasingly interconnected global economic food supply system, national economies and public health are at risk unless an adequate supply of appropriately trained veterinarians who are involved with animals for the food supply is available to counter a wide variety of threats ranging from animal and zoonotic diseases to bioterrorism (DeHaven and Goldberg 2006; Prince et al. 2006). As veterinary medicine faces the challenge of changing to meet the advancing needs of livestock production described above, delay could cause irreparable harm to the profession (Larson 2004). The skills required in twenty-first-century animal agriculture careers, as well as in emerging food systems, ecosystem management and regulatory and bio-security careers, rely on technologies and knowledge that are not restricted to veterinarians (Larson 2004). In this situation, it might seem reasonable to expect more competition from other professions (Nielsen 2003).

The realistic threat of bioterrorism has made it painfully clear that the veterinary profession needs to pay much more 
attention to societal needs (Nielsen 2003). It must be kept in mind that several zoonotic agents also have the potential to be used as biological weapons. Prevention and control of these emerging zoonotic diseases are based on recognition, investigation and collaboration, as well as the development of advanced diagnosis and surveillance tools (Chomel 2003). Especially collaboration is essential. It was noted by DeHaven and Goldberg (2006) that nowadays continued coordination between animal-health and public-health officials is needed. Thus, instead of competition among professions, there should be collaboration with public health officials (DeHaven and Goldberg 2006).

It was recently claimed by Valtonen (2008) that here in Finland we have good and internationally compatible possibilities for co-operation among authorities. This cooperation among different authorities is regulated by laws, and because of the legislation, the roles and actions are clearly defined. However, in a changing world, concepts such as "security" and "co-operation" are also changing (Valtonen 2008). Thus, it is interesting to know how the reality of co-operation is constructed. According to Billig (1987), it could be worthwhile to study the dimension of argumentation when the construction of reality is being investigated. Applying this argumentative and constructive framework to the laws concerning animal diseases will offer a new approach to deal with the question of cooperation among authorities.

\section{Materials and methods}

\section{Aim and materials}

The aim of this study was to investigate how the laws concerning animal diseases construct the reality of cooperation. In other words, how this co-operation can be generated was examined discursively. The interest was descriptive, and the main research questions were (1) what are the linguistic strategies applied to these laws? and (2) how do these legal statements differ verbally from country to country in the Nordic perspective? Thus, the discourses dealing with co-operation among authorities were selected and interpreted on the national, EU and Nordic country levels (see Table 1). These three-dimensional data were needed for comparative analysis because Nordic countries have a different relationship to EU regulations. These regulations were also partly involved in this study when they had strong links to the legislation about animal diseases.

\section{Method}

When social reality is constructed, it is a result of many incomplete, ambiguous and contradictory discourses. The
Table 1 The study design

\begin{tabular}{ll}
\hline Nature of the analysis & Perspective \\
\hline Content analysis & National (Finland, Norway) \\
EU \\
Comparative analysis & $\begin{array}{l}\text { Nordic (Finland, Sweden, Norway and } \\
\text { Denmark: national laws about animal } \\
\text { diseases and EU regulations) }\end{array}$ \\
\hline
\end{tabular}

ability of people to act strategically draws upon these discourses. As a consequence of this, social reality is produced and made through discourses, and social interactions cannot be fully understood without them (Phillips and Hardy 2002, 1-3). This is why the discursive content analysis technique was selected in this case. Phillips and Hardy (2002) also stated that what is important is not a discursive unit (for example, a written text) itself, but the relationships with other texts and their socio-historical contexts. The idea of discourse analysis is a potential method for revealing the processes of social construction that constitute social and organisational life, which makes it a powerful method for studying social phenomena (Phillips and Hardy 2002).

The first aim of this study was to investigate the linguistic strategies and rhetorical characteristics of laws about animal diseases. This is the most important contribution of discourse analysis: it examines how language constructs phenomena (Phillips and Hardy 2002, 6). In this study, research was done by identifying themes and rhetorical strategies, emphasising the disourses about laws concerning animal diseases. It was an interpretive analysis of some forms of text with a view to providing an understanding of discourse and its role in constituting social reality.

\section{Results}

National level

The research proceeded in two phases. First, an analysis of the selected arguments revealed discursive themes called "organisation of co-operation" and "definition of authorities", and a metaphor of "chain reaction effect". Second, the linguistic mechanisms and strategies that supported the emerging discourse were found. The application of the techniques of discourse analysis revealed, for example, a systematic use of orders concerned with hierarchy among authorities. No subjective choices were possible, and the repeated use of verbs such as have to (obey), inform, report, enforce and supervise (both prevention and eradication 
operations) rendered actors passive fulfillers of these legal texts:

...the other institutes are under an obligation to obey the instructions from the Finnish Food Safety Authority... (Animal Diseases Law 55/1980).

The Department of Food and Health in the Ministry of Agriculture and Forestry supervises the prevention of animal diseases and enforces the implementations of the regulations (Animal Diseases Law 55/1980)

...a veterinarian has to report to a municipality veterinarian... and the municipality veterinarian has to do his or her duty by reporting to a veterinarian in the provincial government. And he or she informs authorities in the Finnish Food Safety Authority (Decision of the Ministry of Agriculture and Forestry on notification about animal diseases 1346/1995).

What followed was the discursive chain reaction effect as was noted earlier. This means information flows from municipality veterinarians to veterinarians in the provinces and authorities in the Finnish Food Safety Authority. The animal diseases law determines that veterinarians in municipalities also have several other duties to guarantee the security of both living animals and humans in contact with these animals:

Veterinarians in municipalities have to report to the medical authorities when a health risk for humans is probable. Veterinarians in the municipalities collect samples, and enforce and supervise eradication and disinfection operations together with veterinarians at the provincial level (The Statute on Animal Diseases 601/1980).

Co-operation of veterinarians at different levels is tightly regulated. Before the operations described above, it is necessary for the veterinarians in the provinces to be able to accept these operations. Veterinarians in the provinces have to have control over veterinarians in municipalities so that he or she can instruct them within the framework of the animal diseases law about the duties of and co-operation between veterinarians in municipalities and other local authorities (The Statute on Animal Diseases 601/1980; the instructions of the Ministry of Agriculture and Forestry for the disinfection measures when combating animal diseases 17/EEO/1995; the decision of the Ministry of Agriculture and Forestry on combating BKD disease 3/EEO/2003). However, the instructive and supervising role constructed by these legal orders is changed when co-operation between veterinarians in the provinces and the Finnish Food Safety Authority or Ministry of Agriculture and Forestry is considered:

The Finnish Food Safety Authority, Ministry of Agriculture and Forestry, immediately establishes the national crisis centre and helps both individual provincial veter- inarians participating in eradication operations (e.g., an epidemiological investigation) and veterinarians all over the country. Veterinarians in the provinces have to cooperate (enforce) with the Finnish Food Safety Authority (the decision of the Ministry of Agriculture on combating classical swine fever 22/EE0/2002, foot-and-mouth disease 5/EEO/1996, avian influenza and Newcastle disease 3/EEO/1996, and swine vesicular disease 31/ $\mathrm{EEO} / 1995)$, and when the zones of protection extend to other countries in the EU area, also with authorities in these countries (the decisions of the Ministry of Agriculture and Forestry on combating animal diseases listed previously; 92/119/EEC; 92/66/ETY).

Co-participants on the national level were also directed with simple statements:

When the health risk to humans is obvious, the report to medical authorities must be disseminated (the Statute on Animal Diseases 601/1980).

Police are the responsible authority when executive assistance is needed (the law on easily spreading animal diseases 488/1960).

Veterinarians in the provinces must define the cooperation between veterinarians in municipalities and local fish economy experts (the decision of the Ministry of Agriculture and Forestry on combating BKD disease 3/EEO/2003).

Local hospitals, saunas, laundries and other refineries are obligated to participate in necessary purification and disinfection operations (law on easily spreading animal diseases 488/1960).

If the resources of authorities are insufficient, all veterinarians in Finland (except those over 50 years old) and also veterinary candidates are obligated to participate in eradication processes (law on easily spreading animal diseases 488/1960).

Participants at the international level were not given directions, but clear orders from the EU level were observed:

... it has to be immediately reported to the Commission and other members of the EU. The commission and other members of the EU have to be informed by this country on the development of the situation and operations against the disease (Commission Regulation 1266/2007; Council and Parliament Directive 2001/999/EY).

\section{EU level}

Discursive themes, typical for national legislation, were also found when concentrating on EU regulations. Statements concerned with national prevention programmes 
("there must definitely be suitable national prevention programmes") and information flow from these prevention programmes among countries in the European Union ("there is immediate informing of the Commission and other members of the EU") were included in the theme called "organisation of co-operation". Under this theme, also net-based interaction was organised:

There must definitely be suitable national prevention programmes. In these prevention programmes, clinical, serological and entomological tests must be included. These tests must be organised without shortages and gaps among EU countries. For the efficient flow of information in these prevention programmes, information should be forwarded through the BT-Net system (Council and Parliament Directive 2001/999/EY).

Organisation of co-operation was constructed not only internationally, but also nationally (concerned with the different laws, statutes, decisions, regulations and directives quoted above):

Members of the EU have to report the following to the Commission: (1) any changes, (2) disease breakdowns, (3) protection zones and (4) their prevention programmes and strategies. Disease breakdowns and protection zones also have to be reported to other EU countries.

Members of the EU must have preliminary national prevention programmes. These preliminary programmes can be standardised when necessary in the framework of Commission legislation.

Experts from the Commission can inspect and audit, and can do this in co-operation with legal authorities when necessary.

When the zones of protection extend to other countries in the EU area, authorities in one country are responsible for co-operating with the authorities in these other countries.

Members of the EU are responsible for seeing that the disease is reported to the official authority.

Steps can be taken if the official authority in the original country informs the official authorities in other countries.

Members of the EU have to establish and practically carry out their own national prevention programmes.

Veterinarians (in each country) have to report immediately...to the official authority.

By interpreting this last sentence and associating a direct definition of official authorities, the second theme, "defini- tion of authorities", was developed. Because it was observed that official authorities were defined by characteristics typical for veterinarians (licence to inspect and audit and expertise about veterinary medicine), it involved a short reference to the veterinary profession. It was also highlighted at the EU level that "the member of the EU is responsible for seeing that official veterinarians immediately carry out their official duties". Linguistically, this action was regulated by orders, time definitions (immediately), verbs (have to, standardise, co-operate) and adjectives (responsible). These linguistic strategies were focused on both individual authorities and countries involved in EU organisation.

\section{The Nordic level}

On the Nordic level, there was a comparative study of national legislation and EU regulations. It was noted in the EU regulations that "some countries have no need to establish prevention breeding programmes against scrapie" (EY N:o 546/2006). All of them were Nordic countries: Finland, Sweden and Denmark. Based on data following from the EU regulations and national legislation of Finland, some accurate definitions of authorities and their collaborative actions were evident. In Norway, however, the situation was different. Firstly, legislation concentrating specifically on animal diseases was not found. The themes "organisation of co-operation" and "definition of authorities" had to be established by searching for any laws including references to linguistic constructs such as "animal disease", "prevention of animal disease" or their synonyms.

In selected Norwegian legislation (regulations relating to establishment, operation and disease-prevention measures at fish farms and regulations relating to allocation, establishment, operation and disease-prevention measures at fish hatcheries for salmonids and other freshwater fish), a description of national co-operation and its organisation was clearly stated:

The management plan shall be approved by the Directorate of Fisheries' regional office in consultation with the Norwegian Animal Health Authoritythe chief county veterinary officer.

When farmed fish are found to be or suspected of suffering from an infectious disease, the Norwegian Animal Health Authority, the chief county veterinary officer, in consultation with the Directorate of Fisheries' regional office and the country governor, may order escape monitoring.

In these and one additional sentence focused on below, also a description of the responsible authority and repetition of this definition were made:

...in consultation with the Norwegian Animal Health Authority - the chief county veterinary officer... 
Norwegian Animal Health Authority - central administration...Norwegian Animal Health Authority - central administration.

However, definitions can be incomplete ("fishery protection authority" without explanation) or change from situation to situation. Instead of consistent use of the term "Norwegian Animal Health Authority", several other authorities were also presented:

The ministry may issue regulations regarding the need for type approval.

The regional office of the Directorate of Fisheries shall be informed when new sites are put to use and when production ceases.

Licence holders have a duty to report immediately to the Directorate of Fisheries' regional office...

...without permission from the Directorate of Fisheries or any person so authorised by it.

The Director General of Fisheries may grant dispensation from the density requirement...

The Director General of Fisheries shall decide...

That is why a third theme, "divided authority", was established. Early regulations, together with laws for veterinarians and other animal health professionals, are also important for the prevention of animal diseases and can indicate that it is not only the veterinary profession's duty to prevent and control animal diseases:

Animal health professionals are responsible for... (not only veterinarians).

Biologists and those involved in the speciality of fish health can use drugs for animals in water.

\section{Discussion}

In this study, the laws dealing with animal diseases were analysed. As a result, in agreement with Valtonen (2008), it was found that here in Finland the co-operation between authorities is well organised. In an emergency, there is a "chain reaction effect" among authorities, and the roles and actions are clearly defined. On the national and EU level, there was also a clear concept in naming the responsible authorities. Discursively, it did not seem that the legislation would construct competition among professionals. On the contrary, clear orders may guarantee a better foundation for operations by preventing elements of competition. Of course, this is an ideal situation, as highlighted also by
DeHaven and Goldberg (2006), who noted that not competition but collaboration should be reached.

On the other hand, by interpreting some EU statements and other meaningful national arguments more accurately, it was concluded that in EU legislation the responsibility and independence of each country are highlighted. In the definition of authorities, a topic shared by national legislation and EU regulations, the term "authority" usually is a short reference to veterinary professionals. It was described in the EU regulation as if the veterinarians, not the other public health officials, animal scientists or farmers in a country, were the responsible agents. However, the skills required in animal agriculture nowadays rely on technologies and knowledge that are not restricted to veterinarians (Larson 2004).

This was well noted in the Norwegian legislation. In Norway, the veterinarian was one, but not the only authority. There is an undefined "fishery protection authority" in this country, and Norway has a law for veterinarians and other animal health professionals. Probably biologists with the speciality of fish health can call themselves animal health professionals, but it is not clear if there are others in this authorised sector. It is certain that in specific conditions like in fisheries the need for fish farmers can challenge veterinary services (see Buntain 2004, above), and a new profession can be constructed. Then the relationship between veterinarians and these experts will change. It was already suspected by Nielsen (2003) that this could mean more competition between professions.

In the present study, only arguments about arguments are introduced. It is subjective, but perhaps worthwhile when the construction of reality from written texts is revealed (see Billig 1987; Phillips and Hardy 2002). However, in the future it would be more fruitful to establish an experimental study design. It could involve some authorities practising co-operation in a situation like a real emergency. The question could deal with uniformity of legislation and real action, or changes of opinions about co-operation among authorities.

Conflict of interest There is no conflict of interest. There are no grants to mention.

\section{References}

Billig M (1987) Arguing and thinking. A rhetorical approach to social psychology. Cambridge University Press, London

Buntain B (2004) Emerging challenges in public health protection, food safety and security: veterinary needs in the USDA's food safety and inspection service. J Vet Med Educ 31:334-340

Chomel B (2003) Control and prevention of emerging zoonosis. J Vet Med Educ 30:145-147

DeHaven R, Goldberg R (2006) Animal health: foundation of a safe, secure and abundant food supply. J Vet Med Educ 33:496-501 
Larson R (2004) Food animal veterinary medicine: leading a changing profession. J Vet Med Educ 31:341-346

Maccabe A, Matchett K, Hueston W (2008) The need for public-health veterinarians as seen by future employers. J Vet Med Educ 35:269-274

Nielsen O (2003) Will the veterinary profession flourish in the future? J Vet Med Educ 30:301-307

Phillips N, Hardy C (2002) Discourse analysis. Investigating Processes of Social Construction, Sage
Prince B, Andrus D, Gwinner K (2006) Academic food-supply veterinarians: future demand and likely shortages. J Vet Med Educ 33:517-524

Valtonen V (2008) Sodankäynnin muutos viranomaisyhteistyön näkökulmasta. In: 5th Symposium of Military Sciences. National Defence University and the Finnish Society of Military Sciences. Available via http:/www.mpkk.fi/fi/ajankohtaista/sotatieteidenpaivat/Taktiikan $\% 20$ abstraktit.html. Acccessed 15 Oct 2008 